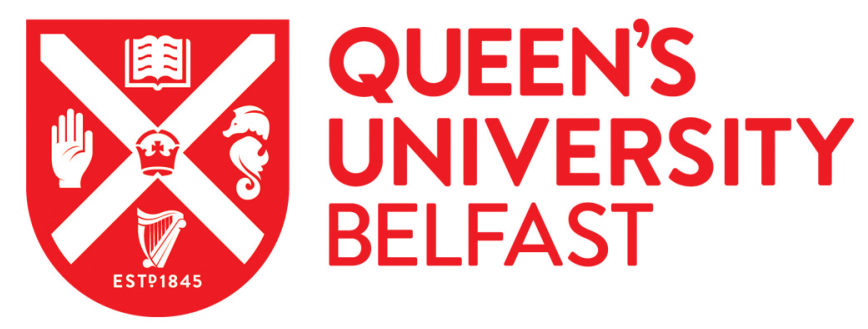

\title{
A longitudinal examination of perceived racial/ethnic discrimination, public ethnic regard and depressive symptoms in Latino youth
}

Stein, G. L., Taylor, L., Kulish, A., \& Gonzalez, L. (2017). A longitudinal examination of perceived racial/ethnic discrimination, public ethnic regard and depressive symptoms in Latino youth. Journal of Community Psychology.

Published in:

Journal of Community Psychology

Document Version:

Peer reviewed version

Queen's University Belfast - Research Portal:

Link to publication record in Queen's University Belfast Research Portal

Publisher rights

Copyright 2017 John Wiley \& son Ltd.

This work is made available online in accordance with the publisher's policies. Please refer to any applicable terms of use of the publisher.

\section{General rights}

Copyright for the publications made accessible via the Queen's University Belfast Research Portal is retained by the author(s) and / or other copyright owners and it is a condition of accessing these publications that users recognise and abide by the legal requirements associated with these rights.

Take down policy

The Research Portal is Queen's institutional repository that provides access to Queen's research output. Every effort has been made to ensure that content in the Research Portal does not infringe any person's rights, or applicable UK laws. If you discover content in the Research Portal that you believe breaches copyright or violates any law, please contact openaccess@qub.ac.uk. 
A Longitudinal Examination of Perceived Racial/Ethnic Discrimination, Public Ethnic Regard and Depressive Symptoms in Latino Youth

Keywords: Latino; Discrimination; Public regard 


\begin{abstract}
This longitudinal study examined the role of perceived racial/ethnic discrimination and public ethnic regard on depressive symptoms in an adolescent Latino sample ( $\mathrm{n}=141)$ living in an emerging immigrant community. Using a cross lagged model, this study found that Time 1 discrimination did not predict Time 2 depressive symptoms, nor vice versa. However, public ethnic regard served as a significant moderator of the longitudinal association of discrimination. For youth who reported high public ethnic regard and high racial/ethnic discrimination at Time 1, they reported greater discrimination at Time 2 compared to those who reported low public ethnic regard. These findings suggest that an internalized positive perception of the public's view of one's ethnic group is a potential vulnerability factor that needs to be better understood. These findings imply the need for additional research on the unique role of public ethnic regard in emerging immigrant communities.
\end{abstract}

Keywords: adolescence, depression, discrimination, ethnic identity, Latino, youth 
A Longitudinal Examination of Perceived Racial/Ethnic Discrimination, Public Ethnic Regard and Depressive Symptoms in Latino Youth

Perceived racial/ethnic discrimination plays a significant role in the prediction of depressive symptoms for Latino youth (e.g., Potochnick \& Perreira, 2010; Author Cite, 2012). This relationship has been borne out with longitudinal studies (e.g., Berkel et al., 2010); however, few studies have examined the longitudinal associations between perceived racial/ethnic discrimination and depressive symptoms in samples of Latino youth in an emerging immigrant community. It is important to examine these longitudinal associations in emerging immigrant communities in particular because Latino youth in these emerging communities (e.g., North Carolina) report greater discrimination compared to Latino youth in well-established Latino communities (e.g., California) (Potochnick, Perreira, \& Fuligni, 2012). Additionally, there has been little empirical attention investigating how these longitudinal associations are mitigated by ethnic identity processes such as public ethnic regard, which is the internalized perception of other's evaluation of one's ethnic group (Rivas-Drake et al., 2014). In emerging immigrant communities, it may be critical to further explore the role of public ethnic regard, as the antiimmigrant rhetoric in these communities has been notable (Lacy \& Odem, 2009), and the ways in which Latino youth in these communities have internalized this rhetoric into an understanding of their ethnicity is not well understood. To address these limitations, the current study examined the longitudinal examinations between perceived ethnic/racial discrimination and depressive symptoms over time and whether public ethnic regard influenced the nature of these associations.

\section{Perceived Racial/Ethnic Discrimination in Emerging Immigrant Communities}

In the past two decades, there has been a significant increase in the Latino population throughout the United States (U.S. Census Bureau, 2010), and this growth has been prominent in 
new areas, such as the South and Midwest, that had not traditionally served as destinations for Latino immigrants (Lichter, Parisi, Taquino, \& Grice, 2010). Compared to established immigrant communities, emerging Latino immigrant communities have fewer immigrant resources and a poorer infrastructure for immigrants due to the lack of an established Latino population (Stamps \& Bohon, 2006). These communities have also witnessed some anti-immigrant rhetoric and racial tensions that were exacerbated during the economic downturn when immigrants were viewed as a population who took jobs and public resources but did not contribute taxes (Crowley \& Lichter, 2009). Given these unique social forces within emerging immigrant contexts, it is imperative to understand how discrimination unfolds and impacts the development of Latino adolescents in this context (Stein, Gonzales, Garcia Coll, \& Prandoni, 2015). It is important to note that discrimination in these communities can be the result of the multiple, intersecting identities that characterize Latino adolescents (e.g., foreigner status, undocumented status, national origin). While more research is necessary to understand the multifaceted experience of discrimination for Latino youth, this study will focus on perceived racial/ethnic discrimination given that the majority of literature has focused on these experiences in adolescence (e.g., Zeiders, Umaña-Taylor, \& Derlan 2013; Rivas-Drake, Hughes, \& Way, 2009).

When comparing Latinos in established immigrant communities to those in emerging ones, Latino adolescents in emerging communities reported greater frequency of discrimination experiences on daily diary measures and also endorsed a greater likelihood of experiencing discrimination (Perreira, Fuligni, \& Potochnick, 2010; Potochnick et al., 2012). These two studies compared the experiences of Latino youth in urban and rural North Carolina (NC) to those in Los Angeles (LA). Regardless of nativity status, rural NC youth reported a greater percentage of days when they experienced negative ethnic treatment than youth in LA, who 
reported the fewest days of negative ethnic treatment (Potochnick et al., 2012). These findings are consistent with sociological work with Latino immigrant adults who report experiences of discrimination in multiple contexts in emerging immigrant Latino communities (e.g., school, government offices, work) (Dalla, Ellis, \& Cramer, 2005; Marrow, 2011; Torres, Popke, \& Hapke, 2006). However, more research is needed to further explore the role of perceived racial/ethnic discrimination for Latino adolescents in these contexts, particularly how these experiences vary over time and influence mental health functioning.

\section{Perceived Racial/Ethnic Discrimination and Depressive Symptoms}

There has been a robust and consistent relationship between experiences of perceived racial/ethnic discrimination and depressive symptoms, and this relationship has been documented for Latino youth in emerging communities (Potochnick \& Perreira, 2010; Author Cite, 2012). According to the integrative model of child development proposed by Garcia Coll and colleagues (1996), experiences of discrimination in the proximal environment are salient predictors of child developmental outcomes but need to be understood within the larger social context. In these emerging immigrant communities, experiences of racial/ethnic discrimination may be particularly harmful psychologically for Latino youth in immigrant families, as these experiences may fuel feelings of powerlessness and hopelessness in an environment that is supposed to be their new home. Consistent with the integrative model, this risk may be magnified as their parents may have less experience with handling racial/ethnic discrimination and be less able to provide ethnic socialization messages about handling discrimination (Roffman, Suarez-Orozco, \& Rhodes, 2003). Furthermore, emerging immigrant communities may also have fewer social resources aimed at maintaining a positive cultural orientation and fewer well-established ethnic enclaves (Stein et al., 2015). 
Taken together, this would suggest that for Latino youth in these communities, experiences of discrimination would be associated with greater depressive symptoms, but few studies have examined this question longitudinally. Past work in established immigrant communities suggests that there is a longitudinal relationship between experiences of discrimination and the prediction of greater depressive symptoms over time for Latino adolescents (Basáñez, Warren, Crano, \& Unger, 2014; Berkel et al., 2010). Thus, we expected that perceived racial/ethnic discrimination in the proximal environment would predict greater depressive symptoms at one year later.

\section{Public Ethnic Regard}

How immigrant groups are received into a community in general has long been a central aspect of acculturation and sociological work with Latinos (e.g., Berry, 2001; Portes \& Rumbaut, 2001), and is now gaining increased attention as an important psychological contributor to the adjustment of Latino youth (Schwartz et al., 2014). As Latino youth in immigrant families experience their receiving context, this likely informs their internal conceptualization of their ethnic group and in particular their public ethnic regard. Public ethnic regard is an important aspect of ethnic identity that has been defined as one's perception of how negatively or positively others evaluate one's ethnic group (Rivas-Drake et al., 2014).

Although ethnic identity serves as one of the most frequently studied protective factors in the relationship between perceived racial/ethnic discrimination and depressive symptoms (Shelton, Yip, Eccles, Chatman, Fuligni, \& Wong, 2005), the role of public ethnic regard in protecting against experiences of racial/ethnic discrimination is not well understood.

Theoretically, it has been argued that a lower public ethnic regard (i.e., feeling that others view one's group more negatively) protects youth when they experience ethnic/racial discrimination 
as the experiences of discrimination are consistent with their worldview (Sellers, Linder, Martin, \& Lewis, 2006; Shelton et al., 2005). Because these youth expect this type of treatment, protection is conferred when they do not make personal attributions to the experiences of discrimination thereby minimizing damage to their self-concept (Neblett, Rivas-Drake, \& Umaña-Taylor, 2012; Sellers, Copeland-Linder, Martin, \& Lewis, 2006; Shelton et al., 2005). And, in fact, one past study with African American youth suggested that lower public ethnic regard protected against depressive symptoms when youth were confronted with discrimination (Sellers et al., 2006).

Yet, other studies have found no protective effect of public ethnic regard on depressive symptoms when youth experience racial/ethnic discrimination (e.g., Rivas-Drake, Hughes, \&Way, 2008; Seaton, Upton, Gilbert, \& Volpe, 2014). For example, in a study of Chinese American youth, public ethnic regard did not moderate the association between ethnic/racial discrimination and depressive symptoms, but instead served to predict fewer depressive symptoms (Rivas-Drake et al., 2008). Although there are no past studies of Latino adolescents examining this precise question, a series of studies by Rivas-Drake $(2011 ; 2012)$ demonstrated the important role of public ethnic regard as a promotive factor for Latino college students such that it predicted fewer depressive symptoms and greater self-esteem. Thus, public ethnic regard can serve as either a promotive factor for Latino youth leading to fewer depressive symptoms over time or as a protective factor by buffering against experiences of racial/ethnic discrimination (Neblett et al., 2012).

However, public ethnic regard may also predict how Latino adolescents perceive their environment and may make them more aware of experiences of racial/ethnic discrimination (Sellers \& Shelton, 2003). For example, in the study conducted by Rivas-Drake (2012) public 
ethnic regard was associated with the sense of community that the Latino college students felt on campus suggesting that public ethnic regard served to help shape the experiences of Latinos within their context. Moreover, in a multi-ethnic adolescent sample, a more negative public ethnic regard was associated with greater perceived racial/ethnic discrimination (Rivas-Drake et al., 2009). This question has yet to be explored in a Latino adolescent sample in an emerging immigrant community, but it is likely that public ethnic regard may influence later perceptions of racial/ethnic discrimination.

\section{Hypotheses}

The current study examines a cross-lagged model of the links between perceived racial/ethnic discrimination, depressive symptoms, and the moderating role of public ethnic regard in a Latino adolescent sample living in an emerging immigrant context. Given the literature review, we hypothesized that racial/ethnic discrimination at $\mathrm{T} 1$ would predict greater depressive symptoms at $\mathrm{T} 2$ and not vice versa. We also explored how public ethnic regard influenced depressive symptoms and perceived racial/ethnic discrimination over time, and predicted that it would be associated with fewer depressive symptoms. Given the limited research on the role of public ethnic regard in predicting discrimination in these communities, we did not have a specific hypothesis for this question. Finally, we hypothesized that public ethnic regard would serve as a protective factor buffering the auto-regressive associations between perceived racial/ethnic discrimination and depressive symptoms across time.

\section{Method}

\section{Participants}

One hundred and forty Latino adolescents participated in a school-based longitudinal study of cultural factors, academic achievement, and psychological functioning ( $53 \%$ female; $\mathrm{M}$ 
$=14.02, S D=1.34$ years old at $\mathrm{T} 1)$. The original sample at $\mathrm{T} 1$ was comprised of 191 Latino adolescents in the $7^{\text {th }}-10^{\text {th }}$ grades living in an emerging immigrant context (see Author cite, 2012 for the description of the original study) in which $78 \%$ were Mexican-origin (the next largest group was mixed Latino heritage that accounted for $8 \%$ of the sample with the remainder of the sample having immigrated from various countries in Central America). In terms of nativity status, $58 \%$ were U.S born, and of those born outside the US, $65 \%$ immigrated at age five or younger (see Author Cite, 2012 for additional information). A follow-up study was conducted one-year later in which 141 of the original sample participated. There were no significant differences between those who participated at both time points on $\mathrm{T} 1$ variables.

\section{Procedure}

The researchers attempted to recruit all Latino $7^{\text {th }}-10^{\text {th }}$ grade students in a rural school district in North Carolina (two middle schools, one high school; $\mathrm{n}=442$ ) that had a large growth in the Latino population. At the time data were collected (2010-2012), the school district (K-12) was 34\% Latino with $68 \%$ of students qualifying for free or reduced lunch (Department of Public Instruction, 2009). In order to participate in the study, parental consent was obtained either at a back-to-school night, through bilingual consent letters sent home, or through phone recruitment. Taken together, 221 parents consented for their child to be in the study (79\% of those reached; $50 \%$ of total) and 40 parents declined participation (14\% of those reached; $9 \%$ of total). All students with parental consents were invited to completed measures in their school cafeteria at a time designated by the school $(\mathrm{n}=192)$. One student declined participation during the school data collection. Students were provided with the option to complete the survey in English or Spanish, and all but one student chose English. Students who participated in the study were then invited to participate in a follow-up study one year later, and students who were at school that day and who 
were in the previous study participated in the follow-up $(n=141)$. Students in the follow-up study were provided with a $\$ 5$ gift card for their participation. All follow-up surveys were completed in English.

\section{Measures}

Perceived racial/ethnic discrimination. The 21-item Way Discrimination Scale (WDS) was used to assess perceived peer racial/ethnic discrimination. The measure was developed based on in-depth, semi-structured interviews with Latino, African American, and Asian American adolescents (Rosenbloom \& Way, 2004). Adolescents reported at T1 and T2 the frequency they had experienced 21 specific discriminatory events due to their "race or ethnicity" from their peers (e.g., other students in school make fun of you; other students expect you will get a bad grade). Adolescents reported their experiences on a 5-point Likert-type scale ranging from (1) "never" to (5) "all the time." This scale has demonstrated adequate psychometric properties in past studies (e.g., Rivas-Drake et al., 2008). In the current sample, the reliabilities at T1 $(\alpha=.95)$ and T2 $(\alpha=.93)$ were excellent.

Depressive symptoms. The 33-item Mood and Feelings Questionnaire (Angold et al., 1987) was used to assess adolescents' depressive symptoms at T1 and T2. Adolescents endorsed on a 3-point Likert-type scale the extent of their depressive symptoms (0) "never true”, (1) "sometimes true", and (2) "mostly true." Sample items include "I felt I was no good" and "I didn't enjoy anything at all." This measure has demonstrated adequate psychometric properties (Burleson Daviss et al., 2006) and was reliable in this sample as well (T1 $\alpha=.94 ; \mathrm{T} 2 \alpha=.93$ ).

Public ethnic regard. An adapted version of the Multidimensional Inventory of Black Identity (MIBI; Sellers, Smith, Shelton, Rowley, \& Chavous, 1998) assessed adolescent's level of public ethnic regard at $\mathrm{T} 1$ and $\mathrm{T} 2$. The adapted version has been used in past research with 
multiple ethnic groups, including Latinos (e.g., Rivas-Drake et al., 2008). The four-item public ethnic regard scale asked adolescents to endorse on a 5-point Likert-type scale their level of agreement about how other's viewed their ethnic group from (1) "Strongly disagree” to (5) "Strongly agree." Sample items include "In general, others groups view my ethnic group in a positive manner" and "In general, others respect members of my ethnic group." The scale has demonstrated adequate psychometric properties (Fuligni, Witkow, \& Garcia, 2005; Kiang, Yip, Gonzales-Backen, Witkow, \& Fuligni, 2006) and good reliability in this sample (T1 $\alpha=.88$, T2 $\alpha=.85)$.

\section{Data Analytic Plan}

Structural equation modeling (SEM) in Amos Graphics 18 was used to examine the paths of interest over time; SEM is an extension of a regression framework, but has the advantages of being able to (a) account for measurement error in scales, (b) model multivariate outcomes, and (c) estimate the concurrent relations among endogenous predictors and exogenous variances. Thus, all hypotheses can be simultaneously tested in a single model. Overall fit was assessed using the guidelines of a $\chi^{2} / d f$ index $\leq 3$, a Tucker Lewis Index (TLI) and comparative fit index $(\mathrm{CFI}) \geq .90$, and a root mean square residual (RMSEA) $\leq .08(\mathrm{Hu} \&$ Bentler, 1999).

The first step in SEM is to build the measurement model through estimating latent variables using manifest indicator, or items from the scales, for the two key constructs (i.e., depression and discrimination). Rather than using each individual item as an indicator, a parceling approach was used because it increases the efficiency of estimation; more specifically, aggregating two or more items into a manifest indicator, or parcel, increases the stability of the factor solution, and the reliability and representativeness of the scale (Little, Cunningham, Shahar, \& Widaman, 2002). The items-to-construct balance approach was used to create each 
parcel for latent variables of discrimination and depression, respectively. In this procedure, the factor loadings are ranked from highest to lowest. As an "anchor," one of the three highest loading items was allocated to each parcel. The remaining items were assigned to each parcel in a snake order (e.g., 1, 6; 2, 5; 3, 4) which achieves a reasonable balance for each parcel.

The discrimination scale had 21 items, so 7 were allocated to each parcel; the depression scale had 33 items, so 11 were assigned to each parcel. For depressive symptoms, the parcels were loaded onto a latent variable at each time point; the latent constructs were allowed to correlate over time for good model fit $\left(\chi^{2}(8)=29.51, p>.05, N=195 ; \chi^{2} / d f=1.19\right.$; TLI = .99; $\mathrm{CFI}=.99 ; \mathrm{RMSEA}=.031(\mathrm{CI}: .001, .093))$. The same steps were repeated for discrimination which also had good model fit $\left(\chi^{2}(8)=17.57, p=.02, N=195 ; \chi^{2} / d f=2.20 ;\right.$ TLI $=.98 ; \mathrm{CFI}=$ .99 ; RMSEA $=.079(\mathrm{CI}: .027, .129))$. Given that the positive bias of the RMSEA is affected by low degrees of freedom (df) (Kenny, 2014), Kenny, Kaniskan and McCoach (2014) have cautioned against computing this fit statistic in small df models. Therefore, although the confidence interval of the RMSEA of the discrimination constructs exceeded the recommended bounds (MacCallum, Brown, \& Sugawara, 1996), the excellent fit statistics across the other approaches justified retaining this model. These measurement models were used for the primary cross-lagged model of interest.

To test for moderation effects on later outcomes, public ethnic regard was added as a manifest variable at Time 1 . Next, to prevent multicollinearity, the centered manifest scale for public ethnic regard was multiplied by each of the centered parcels for discrimination; this yielded three indicators for the latent interaction term. The procedure was repeated for using the centered parcels of depression and public ethnic regard to create a second latent interaction term. Finally, the controls of age and gender were entered as Time 1 and public ethnic regard at Time 
2. All exogenous variables were allowed to correlate with each other and error terms for the endogenous outcomes were also allowed to correlate.

\section{Results}

\section{Preliminary Analyses}

The means, standard deviations and bivariate correlations for all study variables and the composite scales of latent constructs are included in Table 1. Figure 1 depicts the primary model test of the cross-lagged effects of discrimination and depressive symptoms, and the moderating role of public ethnic regard. Endogenous predictors and error variances for exogenous outcomes, respectively were allowed to correlate. The full model had good overall fit $\left(\chi^{2}(99)=299.86, p<\right.$ $\left..05, N=195 ; \chi^{2} / d f=1.704 ; \mathrm{TLI}=.95 ; \mathrm{CFI}=.96 ; \mathrm{RMSEA}=.060(\mathrm{CI}: .048, .072)\right)$. Table 2 includes all of the structural path estimates. The only significant path for the control variables of adolescent age and gender was that boys were less likely to report depressive symptoms compared to girls $(\beta=-.22, p<.05)$. Age did not have a direct effect on depression or discrimination over time. Moreover, the direct effects of public ethnic regard at Times 1 and 2 on depressive symptoms and discrimination at Time 2 were also non-significant.

The auto-regressive controls for each of the main constructs were significant. That is, adolescents higher in depressive symptoms at Time 1 were also higher at Time 2 at the trend level $(\beta=.17, p=.061)$, and youth who perceived greater discrimination at Time 1 also perceived more discrimination at Time $2(\beta=.43, p<.001)$. However, the cross-lagged effects were not significant. Earlier depressive symptoms did not significantly predict Time 2 discrimination, and discrimination did not predict depressive symptoms one year later.

However, the interaction effects for each construct did influence the later outcomes. Adolescents who were higher in discrimination at Time 1, and had a more positive public 
perception of their ethnic group, were more likely to report discrimination at Time $2(\beta=.23, p$ $<.001)$. Thus, there was a stronger relation between perceived discrimination over time for youth with higher, compared to youth who had average or lower, levels of public ethnic regard (Figure 2). There was a trend level interaction between public regard and depressive symptoms at $\mathrm{T} 1$ the trend level $(\beta=-.14, p=.076)$. The analyses suggested that valuing the public view of one's ethnic group was a vulnerability factor for adolescents with regard to discrimination, exacerbating that effect over time.

\section{Discussion}

Latino adolescents in emerging immigrant communities in the South navigate a racial/ethnic landscape that places them at risk for experiencing more racial/ethnic discrimination than Latinos in more established immigrant communities (Potochnick, 2012), but little is known about the longitudinal impact of these experiences on the mental health of Latino adolescents nor how public ethnic regard influences these relationships. The results of our study suggest that public ethnic regard plays a salient role in the longitudinal course of both perceived racial/ethnic discrimination in an emerging immigrant community. Contrary to our hypotheses, ethnic/racial discrimination did not predict greater depressive symptoms over time and this relationship was not buffered by public ethnic regard. Nevertheless, modeling the interaction of public ethnic regard over time enables a greater understanding of the nuanced and oftentimes complicated role that public ethnic regard can play for developing adolescents.

\section{Longitudinal Increases in Perceived Peer Racial/Ethnic Discrimination}

In an emerging immigrant community, on the whole, Latino adolescents who perceived greater levels of racial/ethnic discrimination at $\mathrm{T} 1$ were more likely to have increased levels of perceived peer racial/ethnic discrimination over time compared to those adolescents who 
reported lower levels of peer racial/ethnic discrimination. This finding suggests that as adolescents continue to develop more sophisticated cognitive processes such as abstract and moral reasoning, they may also become more attuned to discriminatory experiences in their environments (Quintana, 2008; Spears, Brown, \& Bilger, 2005). As youth become more aware of these experiences, they demonstrate increases in their reports of perceived racial/ethnic discrimination. This line of reasoning is supported by longitudinal studies that have indeed found significant increases in the reports of the frequency of discrimination across adolescence in Latino and other minority groups (Benner \& Graham, 2011; Juang \& Cookston, 2009). However, other work suggests that perceptions of peer racial/ethnic discrimination do not increase during adolescence (Greene, Way, \& Pahl, 2006; Bellmore, Nishina, You, \& Ma, 2012; White, Zeiders, Knight, Roosa, \& Tein, 2014). Our findings are most consistent with the longitudinal work documenting increases in perceived racial/ethnic discrimination perhaps due to the narrow developmental time frame of all of our studies (primarily $9^{\text {th }}-10^{\text {th }}$ graders; Benner \& Graham; 2011; Juang \& Cookston, 2009). The studies finding no evidence of longitudinal change involved trajectories across a longer developmental period $\left(9^{\text {th }}-12^{\text {th }}\right.$ grade: Greene et al., 2006; Bellmore et al., 2012; $5^{\text {th }}-10^{\text {th }}$ grades; White et al., 2014). This would suggest that there may be unique risk for increases in the perception of discrimination in the early high school period, and more research should further explore this question with a particular focus on examining the underlying processes accounting for the differential findings.

\section{The Role of Public Regard}

More attention needs to be paid to the role of public ethnic regard in influencing perceptions of peer racial/ethnic discrimination. Our findings suggests that perceptions of greater peer racial/ethnic discrimination were particularly strong for those adolescents who reported that 
other ethnic groups have positive evaluations of their ethnic group while at the same time perceiving high levels of discrimination at the first time point. It was for these youth that the increase in peer discrimination was most pronounced compared to those who had reported that other ethnic groups viewed Latinos in a more negative light. This suggests that increases in peer discrimination are not just due to youth finding confirming evidence to their worldview, but rather, that high levels of public ethnic regard may be a liability (Sellers et al., 1998). Although this appears to run counter to predictions that the awareness of negative societal beliefs predicts greater perception of discrimination (Spears, Brown, \& Biegler, 2005), it points to a more complex relationship between perceptions of discrimination and public ethnic regard that may occur in adolescence. At this stage, youth may be integrating their discrete discrimination experiences with a growing awareness of the greater level view of societal based discrimination for those belonging to marginalized groups (Quintana \& Segura-Herrera, 2003). As youth perceive this increased level of racial/ethnic discrimination, this may lead to subsequent decreases in their public ethnic regard over time. Indeed, public ethnic regard tends to decrease during adolescence for ethnic minority youth (Hughes, Way, \& Rivas-Drake, 2011). Our study suggests that this process may be due to increases in youth's perception of racial/ethnic discrimination. Supporting this notion, African American youth who reported greater racial/ethnic discrimination across adolescence subsequently reported lower levels of public ethnic regard (Seaton, Yip, \& Sellers, 2009). Our study is the first to our knowledge to examine how public ethnic regard influences the longitudinal relationship of discrimination at two time points, and it suggests a potential avenue for future work to untangle how ethnic identity processes influence outcomes in adolescence (Umaña-Taylor et al., 2014). 
Paradoxically, studies of Latino youth in emerging immigrant contexts find that, although these youth report higher discrimination then their established immigrant context counterparts, they also report higher levels of school attachment (Potochnick et al., 2012). Consistently, in past analyses with this sample at T1, Latino students reported high levels of peer discrimination and also social support within the schools (Author Cite, 2014). Thus, these Latino youth seem to feel both discriminated against and supported within the same context, which would explain how youth can hold both high levels of public ethnic regard and report high levels of peer racial/ethnic discrimination. In the current analyses, public ethnic regard was not significantly correlated with perceived racial/ethnic peer discrimination at the bivariate level, which suggests that for Latino youth in an emerging immigrant community, other factors may inform their public ethnic regard. Future work should continue to explore predictors of public ethnic regard within an emerging immigrant context like the perceived context of reception, as this is an area of ethnic identity research that has received relatively little empirical attention (Umaña-Taylor et al., 2014).

\section{Depressive Symptoms}

Contrary to our hypotheses, perceived racial/ethnic discrimination did not predict greater depressive symptoms at one year later. While this is not consistent with other work documenting the longitudinal association between peer discrimination and depressive symptoms (e.g., Berkel et al., 2010), it suggests that the relationship between racial/ethnic discrimination and depressive symptoms may be more cross-sectional. This has also been found in past work at this developmental stage. For example, in a sample of Mexican-origin youth, racial/ethnic discrimination assessed at one time point predicted baseline depressive symptoms but not changes over time (Zeiders, et al., 2013). Likewise, in a sample of African American youth, 
racial/ethnic discrimination was associated in baseline psychological functioning, but not to changes in functioning over time (Seaton, Neblett, Upton, Hammond, \& Sellers, 2011). Additional work is necessary to further understand the longitudinal trajectory of perceived racial/ethnic discrimination, and what factors may impact its course. These contradictory findings in the literature may be due to the fact that the measures of perceived ethnic/racial discrimination vary significantly across these studies (e.g., peer vs. societal); the different age ranges of the youth in the studies (ranging from late childhood to early adulthood); and the social context of the population (e.g., diversity of their school contexts).

\section{Future Directions and Limitations}

The current study extends the extant literature on the interrelation between depressive symptoms, perceived racial/ethnic discrimination, and public ethnic regard by examining these questions in an emerging immigrant community Latino sample. While the relationship between depressive symptoms and perceived racial/ethnic discrimination was not evident across time, public ethnic regard emerged as an important moderator of the longitudinal association of perceived racial/ethnic discrimination. Future research should continue to clarify the role of public ethnic regard for adolescents living in these communities, and in particular, disentangle the interrelationship of public ethnic regard, experiences of racial/ethnic discrimination, and perceptions of the receiving community. Future work expanding on how different ethnic groups within a community receive immigrants may be particularly useful to research, especially how this may be similar or different from the national reception. Similarly, work should also focus on whether certain characteristics of the community may also influence these relations (i.e., rurality, racial diversity, foreign-born population, SES) as these have emerged in sociological work as important to the adaption of Latinos in emerging immigrant communities (Lichter, 2012; 
Marrow, 2011). As our study only employed two-time points across two distinct developmental periods (i.e., early and mid-to-late adolescence), future work should also test these questions within distinct developmental periods and with multiple data points to predict depressive symptom trajectories. Additionally, future work should also consider how other aspects of social position influence experiences of discrimination and their emotional ramifications in these emerging immigrant communities (e.g., documentation status, foreigner status; Stein et al., 2015). 


\section{References}

Angold, A., \& Costello, E. J. (1987). Mood and feelings questionnaire (MFQ). Durham, NC: Developmental Epidemiology Program, Duke University.

Basáñez, T., Warren, M. T., Crano, W. D., \& Unger, J. B. (2014). Perceptions of intragroup rejection and coping strategies: Malleable factors affecting Hispanic adolescents' emotional and academic outcomes. Journal of Youth and Adolescence, 43(8), 1266-1280.

Bellmore, A., Nishina, A., You, J. I., \& Ma, T. L. (2012). School context protective factors against peer ethnic discrimination across the high school years. American journal of community psychology, 49(1-2), 98-111.

Benner, A. D., \& Graham, S. (2011). Latino adolescents' experiences of discrimination across the first 2 years of high school: Correlates and influences on educational outcomes. Child development, 82(2), 508-519.

Berkel, C., Knight, G. P., Zeiders, K. H., Tein, J. Y., Roosa, M. W., Gonzales, N. A., \& Saenz, D. (2010). Discrimination and adjustment for Mexican American adolescents: A prospective examination of the benefits of culturally related values. Journal of Research on Adolescence, 20(4), 893-915.

Berry, J. W. (2001). A psychology of immigration. Journal of social issues, 57(3), 615-631.

Burleson Daviss, W., Birmaher, B., Melhem, N. A., Axelson, D. A., Michaels, S. M., \& Brent, D. A. (2006). Criterion validity of the Mood and Feelings Questionnaire for depressive episodes in clinic and non-clinic subjects. Journal of Child Psychology and Psychiatry, 47(9), 927-934. 
Coll, C. G., Crnic, K., Lamberty, G., Wasik, B. H., Jenkins, R., Garcia, H. V., \& McAdoo, H. P. (1996). An integrative model for the study of developmental competencies in minority children. Child development, 67(5), 1891-1914.

Crowley, M., \& Lichter, D. T. (2009). Social Disorganization in New Latino Destinations?*. Rural Sociology, 74(4), 573-604.

Dalla, R. L., Ellis, A., \& Cramer, S. C. (2005). Immigration and rural America: Latinos' perceptions of work and residence in three meatpacking communities. Community, Work and Family, 8(2), 163-185.

Department of Public Instruction. (2009). North Carolina public schools: Statistical profile. Raleigh, NC: State Board of Education.

Downey, G., Eccles, J., \& Chatman, C. (Eds.). (2006). Navigating the future: Social identity, coping, and life tasks. New York, NY: Russell Sage Foundation.

Fuligni, A. J., Witkow, M., \& Garcia, C. (2005). Ethnic identity and the academic adjustment of adolescents from Mexican, Chinese, and European backgrounds. Developmental Psychology, 41(5), 799-811.

Greene, M. L., Way, N., \& Pahl, K. (2006). Trajectories of perceived adult and peer discrimination among Black, Latino, and Asian American adolescents: Patterns and psychological correlates. Developmental psychology, 42(2), 218.

Hu, L. T., \& Bentler, P. M. (1999). Cutoff criteria for fit indexes in covariance structure analysis: Conventional criteria versus new alternatives. Structural Equation Modeling: A Multidisciplinary Journal, 6(1), 1-55. 
Hughes, D., Way, N., \& Rivas-Drake, D. (2011). Stability and change in private and public ethnic regard among African American, Puerto Rican, Dominican, and Chinese American early adolescents. Journal of Research on Adolescence, 21(4), 861-870.

Juang, L. P., \& Cookston, J. T. (2009). Acculturation, discrimination, and depressive symptoms among Chinese American adolescents: A longitudinal study. The journal of primary prevention, 30(3-4), 475-496.

Kenny, D. A., (2014). Measuring model fit [Webpage]. Retrieved from http://davidakenny.net/cm/fit.htm

Kenny, D. A., Kaniskan, B., \& McCoach, D. B. (2014). The performance of RMSEA in models with small degrees of freedom. Sociological Methods \& Research, 0049124114543236.

Kiang, L., Yip, T., Gonzales-Backen, M., Witkow, M., \& Fuligni, A. J. (2006). Ethnic identity and the daily psychological well-being of adolescents from Mexican and Chinese backgrounds. Child Development, 77(5), 1338-1350.

Lichter, D. T. (2012). Immigration and the New Racial Diversity in Rural America. Rural Sociology, 77(1), 3-35.

Lichter, D. T., Parisi, D., Taquino, M. C., \& Grice, S. M. (2010). Residential segregation in new Hispanic destinations: Cities, suburbs, and rural communities compared. Social Science Research, 39(2), 215-230.

Little, T. D., Cunningham, W. A., Shahar, G., \& Widaman, K. F. (2002). To parcel or not to parcel: Exploring the question, weighing the merits. Structural equation modeling, $9(2)$, $151-173$ 
MacCallum, R. C., Browne, M. W., \& Sugawara, H. M. (1996). Power analysis and determination of sample size for covariance structure modeling. Psychological methods, 1(2), 130-149.

Marrow, H. (2011). New destination dreaming: Immigration, race, and legal status in the rural American South. Palo Alto, CA: Stanford University Press.

Neblett, E. W., Rivas-Drake, D., \& Umaña-Taylor, A. J. (2012). The promise of racial and ethnic protective factors in promoting ethnic minority youth development. Child Development Perspectives, 6(3), 295-303.

Lacy, E. C., \& Odem, M. E. (2009). Popular attitudes and public policies: Southern responses to Latino immigration. In M. E. Odem \& E. C. Lacy (Eds.), Latino Immigrants and the Transformation of the US South. Athens, GA: University of Georgia Press.

Perreira, K. M., Fuligni, A., \& Potochnick, S. (2010). Fitting in: The roles of social acceptance and discrimination in shaping the academic motivations of Latino youth in the U.S. Southeast. Journal of Social Issues, 66(1), 131-153.

Portes, A., \& Rumbaut, R. G. (2001). Legacies: The story of the immigrant second generation. Berkeley, CA: University of California Press.

Potochnick, S. R. (2012). The academic adaptation of children of immigrants in new and traditional settlement communities: The role of family, schools, neighborhoods, and state level-policies (Doctoral dissertation). Retrieved from ProQuest. (3512677)

Potochnick, S. R., \& Perreira, K. M. (2010). Depression and anxiety among first-generation immigrant Latino youth: key correlates and implications for future research. The Journal of nervous and mental disease, 198(7), 470-477. 
Potochnick, S., Perreira, K. M., \& Fuligni, A. (2012). Fitting in: The roles of social acceptance and discrimination in shaping the daily psychological well-being of Latino youth. Social Science Quarterly, 93(1), 173-190.

Quintana, S. M. (2008). Racial perspective taking ability: Developmental, theoretical, and empirical trends. Handbook of race, racism, and the developing child, 16-36.

Quintana, S. M., \& Segura-Herrera, T. A. (2003). Developmental transformations of self and identity in the context of oppression. Self and Identity, 2(4), 269-285.

Rivas-Drake, D. (2011). Ethnic-racial socialization and adjustment among Latino college students: The mediating roles of ethnic centrality, public regard, and perceived barriers to opportunity. Journal of Youth and Adolescence, 40(5), 606-619.

Rivas-Drake, D. (2012). Ethnic identity and adjustment: The mediating role of sense of community. Cultural Diversity and Ethnic Minority Psychology, 18(2), 210-215.

Rivas- Drake, D., Hughes, D., \& Way, N. (2008). A closer look at peer discrimination, ethnic identity, and psychological well-being among urban Chinese American sixth graders. Journal of Youth and Adolescence, 37(1), 12-21.

Rivas-Drake, D., Hughes, D., \& Way, N. (2009). A preliminary analysis of associations among ethnic-racial socialization, ethnic discrimination, and ethnic identity among urban sixth graders. Journal of Research on Adolescence 19(3), 558-584.

Rivas-Drake, D., Seaton, E. K., Markstrom, C., Quintana, S., Syed, M., Lee, R. M., ...Yip, T. (2014). Ethnic and Racial Identity in Adolescence: Implications for Psychosocial, Academic, and Health Outcomes. Child development, 85(1), 40-57.

Roffman, J. G., Suarez-Orozco, C., \& Rhodes, J. E. (2003). Facilitating positive development in immigrant youth. In F. A. Villarruel, D. F. Perkins, L. M. Borden, \& J. G Keith (Eds.), 
Community youth development: Programs, policies, and practices, (pp. 90-117). Thousand Oaks, CA: Sage.

Rosenbloom, S. R., \& Way, N. (2004). Experiences of discrimination among African American, Asian American, and Latino adolescents in an urban high school. Youth \& Society, 35(4), $420-451$.

Schwartz, S. J., Unger, J. B., Lorenzo-Blanco, E. I., Des Rosiers, S. E., Villamar, J. A., Soto, D. W., ... \& Szapocznik, J. (2014). Perceived context of reception among recent Hispanic immigrants: Conceptualization, instrument development, and preliminary validation. Cultural Diversity and Ethnic Minority Psychology, 20(1), 1-15.

Seaton, E. K., Neblett, E. W., Upton, R. D., Hammond, W. P., \& Sellers, R. M. (2011). The moderating capacity of racial identity between perceived discrimination and psychological well-being over time among African American youth. Child development, 82(6), 1850-1867.

Seaton, E. K., Upton, R., Gilbert, A., \& Volpe, V. (2014). A moderated mediation model: Racial discrimination, coping strategies, and racial identity among Black adolescents. Child Development, 85(3), 882-890.

Seaton, E. K., Yip, T., \& Sellers, R. M. (2009). A longitudinal examination of racial identity and racial discrimination among African American adolescents. Child Development, 80(2), 406-417.

Sellers, R. M., Copeland-Linder, N., Martin, P. P., \& Lewis, R. L. (2006). Racial identity matters: The relationship between racial discrimination and psychological functioning in African American adolescents. Journal of Research on Adolescence, 16(2), 187-216. 
Sellers, R. M., \& Shelton, J. N. (2003). The role of racial identity in perceived racial discrimination. Journal of personality and social psychology, 84(5), 1079-1092.

Sellers, R. M., Smith, M. A., Shelton, J. N., Rowley, S. A., \& Chavous, T. M. (1998). Multidimensional model of racial identity: A reconceptualization of African American racial identity. Personality and Social Psychology Review, 2(1), 18-39.

Shelton, J.N., Yip, T., Eccles, J., Chatman, C. M., Fuligni, A. J., \& Wong, C. (2005). Ethnic identity as a buffer in psychological adjustment. In G. Downey, J. Eccles \& C. M. Chatman (Eds.), Navigating the Future: Social Identity, Coping and Life Tasks. New York, NY: Russell Sage Foundation.

Spears Brown, C., \& Bigler, R. S. (2005). Children's perceptions of discrimination: A developmental model. Child development, 76(3), 533-553.

Stamps, K., \& Bohon, S. A. (2006). Educational Attainment in New and Established Latino Metropolitan Destinations*. Social Science Quarterly, 87(5), 1225-1240.

Torres, R. M., Popke, E. J., \& Hapke, H. M. (2006). The South's silent bargain: Rural restructuring, Latino labor and the ambiguities of migrant experience. In H. A. Smith \& O. J. Furuseth (Eds.), Latinos in the New South: Transformations of Place (pp. 37-67). Burlington, VT: Ashgate.

Umaña-Taylor, A. J., Quintana, S. M., Lee, R. M., Cross, W. E., Rivas-Drake, D., Schwartz, S. J., ...Seaton, E. (2014). Ethnic and racial identity during adolescence and into young adulthood: An integrated conceptualization. Child development, 85(1), 21-39.

U.S. Census Bureau (2010). The Hispanic Population: 2010. Retrieved from https://www.census.gov/prod/cen2010/briefs/c2010br-04.pdf. 
White, R. M., Zeiders, K. H., Knight, G. P., Roosa, M. W., \& Tein, J. Y. (2014). Mexican origin youths' trajectories of perceived peer discrimination from middle childhood to adolescence: Variation by neighborhood ethnic concentration. Journal of youth and adolescence, 43, 1-15.

Zeiders, K. H., Umaña-Taylor, A. J., \& Derlan, C. L. (2013). Trajectories of depressive symptoms and self-esteem in Latino youths: Examining the role of gender and perceived discrimination. Developmental psychology, 49(5), 951-963. 
Table 1

\begin{tabular}{|c|c|c|c|c|c|c|c|c|c|c|}
\hline \multicolumn{11}{|c|}{ Means, Standard Deviations, and Bivariate Correlations for All Study Variables (T1 N=191; T2 N=141) } \\
\hline & & M & $S D$ & 1 & 2 & 3 & 4 & 5 & 6 & 7 \\
\hline 1 & Male & $47 \%$ & & - & & & & & & \\
\hline 2 & Age (T1) & 14.02 & 1.34 & $.154^{*}$ & - & & & & & \\
\hline 3 & Public Ethnic Regard (T1) & 3.67 & .93 & .018 & -.112 & - & & & & \\
\hline 4 & Public Ethnic Regard (T2) & 3.78 & .83 & .068 & .008 & $.393 * *$ & - & & & \\
\hline 5 & Discrimination (T1) & 1.59 & .67 & .134 & $.233^{* *}$ & -.050 & -.084 & - & & \\
\hline 6 & Discrimination (T2) & 1.49 & .55 & $.173^{*}$ & .121 & -.070 & -.121 & $.463^{* *}$ & - & \\
\hline 7 & Depression (T1) & .29 & .32 & -.111 & .071 & $-.156^{*}$ & .029 & $.297^{* *}$ & $.149^{*}$ & - \\
\hline 8 & Depression (T2) & .29 & .33 & $-.201^{*}$ & .056 & -.081 & -.071 & .086 & $.410^{* *}$ & $.194^{*}$ \\
\hline
\end{tabular}

$\frac{8 \text { Depression }(\mathrm{T} 2)}{\text { Note: }}{ }^{*} p<.05 ; * *<<.01$ 
Table 2

Unstandardized, Standardized, and Significance Levels for Full Model Test (Standard Errors in Parenthesis; N=141)

\begin{tabular}{lccc}
\hline Parameter Estimate & Unstandardized & Standardized & $p$ \\
\hline Discrimination T1 $\rightarrow$ Discrimination T2 & $0.324(.06)$ & 0.43 & $* * *$ \\
Depression T1 $\rightarrow$ Depression T2 & $0.163(.09)$ & 0.17 & 0.061 \\
Depression T1 $\rightarrow$ Discrimination T2 & $0.121(.09)$ & 0.11 & 0.17 \\
Discrimination T1 $\rightarrow$ Depression T12 & $0.048(.06)$ & 0.07 & 0.43 \\
Male $\rightarrow$ Discrimination T2 & $0.502(.58)$ & 0.07 & 0.39 \\
Male $\rightarrow$ Depression T2 & $-1.445(.57)$ & -0.22 & $*$ \\
Age T1 $\rightarrow$ Discrimination T2 & $0.086(.22)$ & 0.03 & 0.69 \\
Age T1 $\rightarrow$ Depression T2 & $0.094(.21)$ & 0.04 & 0.65 \\
Public Ethnic Regard (PER) T1 $\rightarrow$ Depression T2 & $-0.047(.08)$ & -0.05 & 0.57 \\
Public Ethnic Regard (PER) T1 $\rightarrow$ Discrimination T2 & $0.031(.08)$ & -0.03 & 0.71 \\
Public Ethnic Regard (PER) T2 $\rightarrow$ Depression T2 & $-0.050(.08)$ & -0.05 & 0.57 \\
Public Ethnic Regard (PER) T2 $\rightarrow$ Discrimination T2 & $-0.096(.09)$ & -0.08 & 0.30 \\
Discrimination X PER $\rightarrow$ Discrimination T2 & $0.055(.02)$ & 0.25 & $* * *$ \\
Depression X PER $\rightarrow$ Depression T2 & $-0.042(.02)$ & -0.14 & 0.08 \\
\hline
\end{tabular}

Note: $* p<.05 ; * * p<.01 ; * * * p<.001$

Measurement model parameters available upon request. 
Figure 1. Simplified cross-lag model, including all significant direct and moderation effects of interest. Black full lines represent significant paths, dashed lines represent trends, and dotted lines are non-significant. Correlation coefficients for exogenous variables and error variances for endogenous outcomes were omitted from the model for readability. ${ }^{t} p<.10,{ }^{*} p<.05,{ }^{* *} p<.01,{ }^{* * *} p<.001$.

Model Fit: $\chi^{2}(99)=299.86, p<.05, N=195 ; \chi^{2} / d f=1.704 ; \mathrm{TLI}=.95 ; \mathrm{CFI}=.96 ;$ RMSEA $=.060$ (CI: $.048, .072$

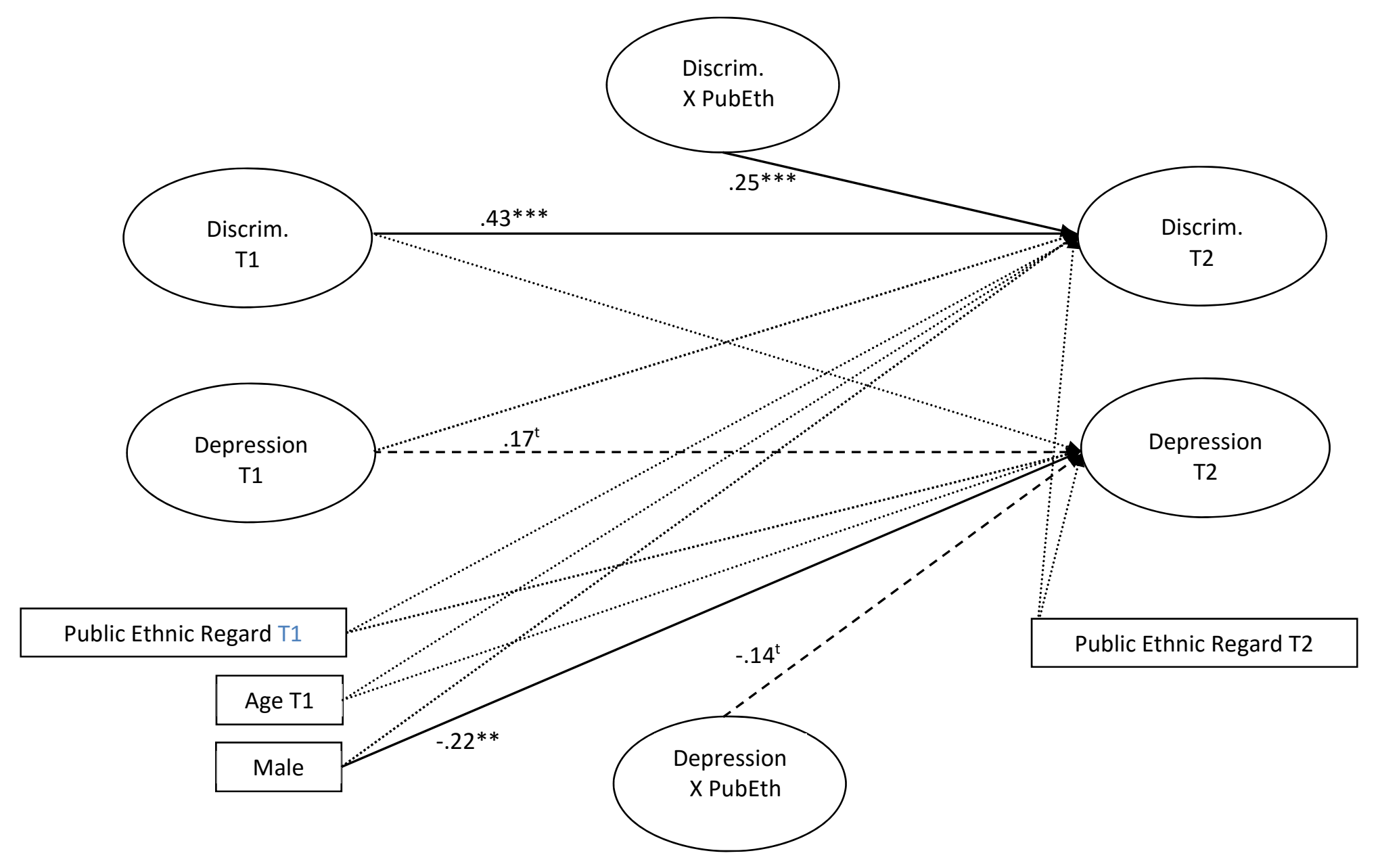


Figure 2. Interaction of centered discrimination $\mathrm{x}$ public ethnic regard. the longitudinal relation discrimination is stronger for youth with higher public ethnic regard. Higher/lower public ethnic regard depicted at $\pm 1 \mathrm{SD}$; Higher/lower discrimination at time 1 depicted at $\pm 1 \mathrm{SD}$.

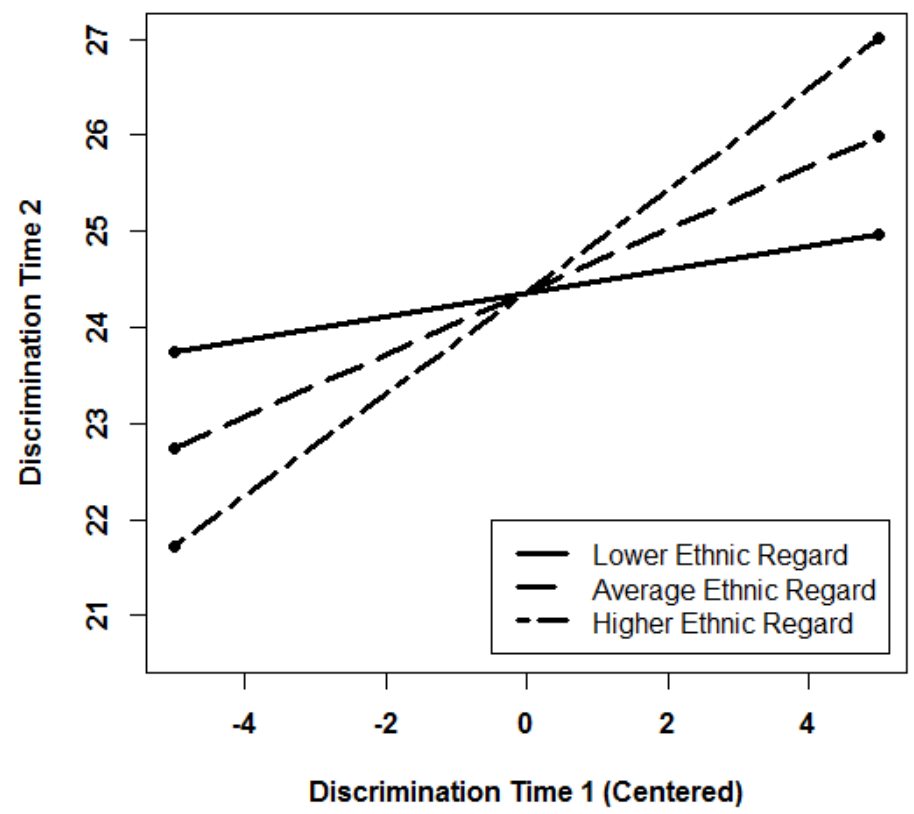

